Adapting to financial pressure on household food budgets in Denmark Associations with life satisfaction and dietary health

Holm, Lotte; Nielsen, Annemette Ljungdalh; Lund, Thomas Bøker

Published in:

Acta Sociologica

DOI:

$10.1177 / 0001699318810095$

Publication date:

2020

Document version

Peer reviewed version

Citation for published version (APA):

Holm, L., Nielsen, A. L., \& Lund, T. B. (2020). Adapting to financial pressure on household food budgets in Denmark: Associations with life satisfaction and dietary health. Acta Sociologica, 63(2), 191-208.

https://doi.org/10.1177/0001699318810095 
Final manuscript accepted for publication in Acta Sociologica. October 2018.

Holm, L., Nielsen, A. L., \& Lund, T. B. (2018). Adapting to financial pressure on household food budgets in Denmark: Associations with life satisfaction and dietary health. Acta Sociologica.

https://doi.org/10.1177/0001699318810095

Adapting to financial pressure on household food budgets in Denmark: associations with life satisfaction and dietary health

Lotte Holm*, Annemette Ljungdalh Nielsen\# and Thomas Bøker Lund*

*Department of Food and Resource Economics, University of Copenhagen, Denmark

\# Health and Care Adminisration, Municipality of Copenhagen, Denmark

Contact:

Loho@ifro.ku.dk 
Final manuscript accepted for publication in Acta Sociologica. October 2018.

\author{
Original Article
}

\title{
Adapting to financial pressure on household food budgets in Denmark: Associations with life satisfaction and dietary health
}

\begin{abstract}
In countries with wide income differentials, food insecurity leads to substantial changes in everyday food practices and to poor dietary and mental health. Less is known about consequences of food budget pressure in affluent populations and in social-democratic welfare societies with narrower income differentials. The paper describes relations between pressure on household food budgets and demographic factors in Denmark. It asks how budgetary constraint relates to life satisfaction and dietary health and how these relationships are affected when people adapt their food practices to manage pressure on budgets. Data from a representative 2015 survey of Danish households are employed. Levels of food budget pressure vary with income and household composition and are negatively associated with life satisfaction and dietary health. We find a sequence of food practice adaptations where changes in food quality, hospitality and seeking external help were being made when adjustments to food provisioning and kitchen practices were proving to be insufficient We conclude that also in affluent social-democratic welfare societies pressure on food budgets has negative impacts on life satisfaction and health. Food budget pressure should be monitored in the future and addressed in public health policy.
\end{abstract}

\section{Keywords}

Food insecurity, health inequality, food consumption practices, life satisfaction, dietary health, social-democratic welfare society, coping, food budget pressure. 


\section{Introduction}

Denmark enjoys one of the highest levels of income equality among OECD countries (OECD, 2017), but when it comes to the population's health there is a marked inequality, and in spite of political efforts to curb it, health inequality has almost doubled over the past 20 years (Koch et al., 2012). Food consumption is one contributing factor to this inequality. Unhealthy food consumption patterns are linked to cardiovascular disease, type- 2 diabetes and obesity and they are strongly socially graded in the Danish population, being more than five times more prevalent in the lower strata of the population compared to the higher social strata ( $27 \%$ and $5 \%$ respectively) (Sundhedsstyrelsen, 2018). In public debate in Denmark this difference is often seen as the result of cultural difference linked to variations in educational level in the population rather than caused by differences in material resources (Fødevarestyrelsen, 2018), and in public health policy the role of social conditions are downplayed (Vallgårda, 2011).

In this paper, we want to challenge this understanding by presenting an analysis of how people in Denmark adapt to financial pressure on their food budgets. We ask how financial pressure, adaptation of food practices and well-being and health are interrelated. The data we use stem from a representative household survey we conducted in 2015 as part of a large study about the experience and handling of financial pressure on food budgets in the Danish population. In the study, we use the term 'food budget pressure' to refer to situations where people to various degrees experience a need to reduce their expenditure on food. The term 'food security' refers to situations where people experience no such need, and the term 'food insecurity' to situations 
Final manuscript accepted for publication in Acta Sociologica. October 2018.

where food budget pressure reaches the levels, which are in focus in the international research about food insecurity.

\section{Food budget pressure and food insecurity}

Food fulfills basic biological needs, necessary for health and survival but the management of food and eating is also an important practice in everyday life, which organizes social interaction and is closely related to life satisfaction. Through food and meals, people express cultural belonging and identity, and meals routinely bring social groups together on a daily basis (Holm, 2013). It follows that for most people food and eating are important for their general quality of life and in studies of life satisfaction meals are one of the daily activities which score highest in terms of joy and wellbeing (Csikszentmihalyi, 1997: 34 ff; Csikszentmihalyi and Hunter, 2014; Krueger et al., 2009). How people adapt their food practices when being faced with financial pressure may then influence their overall life satisfaction.

In international research Food insecurity is the key term used to study this issue. Food insecurity refers to the "inability to acquire or eat an adequate quality or sufficient quantity of food in socially acceptable ways (or the uncertainty of being able to do so)" (Dowler and O'Connor, 2012:45). In high-income countries with wide income differentials such as the US, Australia, United Kingdom, France and Canada, food insecurity has been routinely monitored or addressed (Bates et al., 2017; Bocquier et al., 2015; Coleman-Jensen et al., 2016; Nolan et al., 2006; Tarasuk et al., 2014) but this issue has only recently been taken up in social research in Scandinavian countries (Borch and Kjærnes 2016, Lund et al., 2018). In European statistics of poverty and social exclusion access to food is used as one of several measures of material deprivation (Eurostat, 2016), but no 
Final manuscript accepted for publication in Acta Sociologica. October 2018.

specific monitoring is devoted to food deprivation. This is also the case in Scandinavian countries, such as Denmark, where research on poverty has no special focus on food consumption.

Negative impacts of food insecurity on life satisfaction are documented in qualitative in-depth studies showing that food insecurity often leads to feelings of deprivation, lack of choice, social isolation and anxiety over one's ability to provide for basic needs and feed children (Burns et al., 2013; Devine et al., 2006; Radimer et al., 1992,Dowler, 1997). Further, larger-scale survey studies show that food insecurity and mental health are negatively associated (Heflin et al., 2005; Whitaker et al., 2006) and in Denmark food insecurity is associated with low levels of lifesatisfaction and psychological distress (Lund et al., 2018). Whether such associations also exist for less severe food budget pressure has not been examined.

It is well established that low income is associated with poorer dietary health. The diets of lowincome groups are typically high and dense in energy, containing substantial amounts of saturated fat and sugar, and less in the way of vegetables, fish and fiber than is recommended (Darmon and Drewnowski, 2008). The social grading of food consumption in Denmark is similar, with individuals with lower levels of education consuming less fruit and vegetables and more fatty foods (Groth, Fagt and Brøndsted, 2001). A number of studies show that food insecurity is associated with poor diets known to increase the risk of chronic disease (Leung et al., 2017; Simmet et al., 2017), and that food insecurity is associated with adult obesity, diabetes, and poor mental health (Gundersen and Ziliak, 2015; Hadley and Crooks, 2012). In Danish households with low and very low food security adults are found to have less healthy diets than adults do in food secure households (Lund et al., 2018). Despite this research activity, little is known about whether, and to what degree, more modest forms of food budget restriction are negatively associated with dietary health. A 
Final manuscript accepted for publication in Acta Sociologica. October 2018.

study from the US suggests that households which are not food insecure but experience significant food budget pressure share socio-economic conditions with food insecure households (ColemanJensen, 2010). This may imply that they will be subject to the same risks of adverse outcomes, but this needs to be confirmed empirically.

While European statistics register material deprivation at a general level (Eurostat, 2016) less is known about the everyday practices surrounding the measured material indicators. However, these practices may contribute to promote or inhibit adverse outcomes. They are therefore important to study in quantitative social inequality research. Indeed, in the food consumption area, plenty of qualitative studies suggest an important connection between responses to budget constraints, life satisfaction and the healthiness of food. People experiencing food insecurity adapt their food practices in various ways relating to food provisioning, to the quality or quantity of foods consumed, to the social organization of meals, and to dependence on gifts or loans to obtain sufficient food (Kempson et al., 2002; Alkon et al., 2013; Burns et al., 2013; Canvin et al., 2009; Kaiser and Hermsen, 2015; Pfeiffer et al., 2011). Such experiences may influence quality of life and mental health, due to forced alterations of diets in a more monotonous, and inadequate direction (Tarasuk \& Maclean, 1990; Hamelin, Beaudry, \& Habicht, 2002; Nielsen et al., 2015). Further, preoccupation with access to enough food induce stress and anxiousness, powerlessness, guilt and shame along with fear of being excluded from society (Hamelin, Beaudry, \& Habicht, 2002; Purdam, Garratt, and Esmail, 2015). Recently, quantitative scales to assess hunger-coping behaviors in very low-income populations have been developed and tested (Pinard et al., 2016), but at the time of the survey reported here, these scales were unpublished, and their relevance for higher income populations is unknown. A Danish study showed that the ways households changed their practices with respect to shopping, storing, cooking and eating varied with levels of 
Final manuscript accepted for publication in Acta Sociologica. October 2018.

food budget pressure (Nielsen et al., 2015). To our knowledge, no quantitative studies analyze whether, or how, different ways of adapting to food budget pressure affect life satisfaction or healthiness of food consumption.

The role of food prices for the social distribution of unhealthy food consumption is contested. On the one hand, food prices have been highlighted as one important mediator of the social gradient, as high-energy-density diets are associated with lower costs. In consumer studies and media debate about barriers to healthy eating food prices and the cost of healthy diets surface (Kneafsey et al., 2013). In the US the cost of food relative to income has been found to be the major obstacle preventing low-income families from accessing the foods they prefer (Alkon et al., 2013), and in United Kingdom a growing price gap between more and less healthy foods has been documented (Jones et al., 2014). On the other hand, it has been maintained that healthy diets need not be costly (Saxe, 2011). Mathematical modelling has demonstrated that nutritional recommendations for healthy diets can be followed at very low cost when foods are selected to optimize nutrient content (Parlesak et al., 2016). In principle, then, diets can be healthy without imposing extra costs on consumers. Whether in practice people actually adapt to food budget pressure in manners which conform to this (i.e. by concurrently reducing costs and maintaining the healthiness of the diet) is an empirical question which existing research suggest to answer negatively (Leung et al., 2017; Simmet et al. 2017). However, the food insecurity research only addresses low-income populations and it is not known whether there are similar consequences in social-democratic welfare regimes. Here public policy and services are generally known to provide its citizens a socially acceptable standard of living independently of labour market participation (Esping-Andersen, 1990). This suggests that no citizen should lack access to adequate quantities and qualities of food due to insufficient income. Whether this is the case is however also an 
Final manuscript accepted for publication in Acta Sociologica. October 2018.

empirical question. Within the international food insecurity research more knowledge has been called for about the responses of less vulnerable, higher-income populations to food budget pressure (Ashby et al., 2016). Learning how higher-income populations adapt to financial pressure can add to current research by providing knowledge about earlier phases in the development of food insecurity. On this background, we initiated a study on food budget pressure in Denmark

\section{The study}

How people respond to food budget pressure is a focal point in the study. In food insecurity research the term 'coping strategies' is used to describe changes people make in their daily foodrelated habits (Kempson et al., 2002; alkon et al., 2013; Kaiser and Hermsen, 2015; Devine et al., 2006). The term 'coping' derives from social-psychology, where it has been defined as individuals' 'cognitive and behavioral efforts to manage specific external and/or internal demands that are appraised as taxing or exceeding the person's resources' (Folkman et al., 1986 p. 993), or as 'endeavors to minimize stress in terms of loss of resources' (Hobfoll, 2010). However, this perspective cannot stand alone. Sociological research drawing on newer practice theory (Halkier et al., 2011) suggests that food consumption is a social practice, i.e. a routinized type of behavior which combines materials, competences, knowhow and meanings (Warde, 2016). It is a weakly regulated 'compound' practice, i.e. a practice where standards are not uniform but draws on several autonomous sets of standards such as culinary culture, nutrition, cooking, etiquette and gastronomy (Warde, 2013). At the same time food consumptions it a kind of practice that is performed in conjunction with other practices such as sustaining energy to keep going, resting, celebrating, orchestrating family life, etc. It follows that food consumption practices are 
Final manuscript accepted for publication in Acta Sociologica. October 2018.

performed in many different ways. They are not performed according to strategic decision but when people respond to given situations by implementing procedures they anticipate as being suitable (Warde, 2016). Financial and food budget pressure change the situation people find themselves in and we use the term 'adaptation' rather than 'coping' when describing the changes that people make when facing food budget pressure. We do so to underline that we see such changes as formed by the options and triggers in situations rather than by individual strategic decision making according to well-defined goals.

The study is part of a larger project which included a qualitative interview study, a representative household survey combined with registry data about socio-economic factors, and analyses of food purchase data from a large household panel (GfK Scandinavia). Results have already been published about the experience of and adaptation of practices to food budget pressure (Nielsen et al., 2015; Nielsen and Holm, 2016), consequences of unemployment for food consumption (Smed et al., 2018) and the prevalence of food insecurity in the Danish population and its association with eating- and health-related variables (Lund et.al., 2018). In the current paper we focus on the full spectrum of food budget pressure ranging from food security to food insecurity. We analyze how houeholds adapt their food practices to budget pressure and which consequences this may have for wellbeing and health. The analysis is based on data from the aforementioned household survey. With a quantitative method we abstain from in-depth analysis of performance of food consumption practices. However, we believe that it is possible to address reflections of these practices by focusing on the actions people report when engaging in food practices and the foods they consume. 
Final manuscript accepted for publication in Acta Sociologica. October 2018.

In the following we describe how degrees of food budget pressure relate to socio-demographic factors and to life satisfaction and healthiness of food consumption. We then analyze how people adapt to food budget pressure and how ways of doing so vary with degree of food budget pressure. Finally, we analyze how the different ways of adapting relate to life satisfaction and healthiness of food consumption. We end by discussing implications of our analysis. But first we describe our methodology and the measures used.

\section{Methods and material}

The study employed a cross-sectional, questionnaire-based survey carried out in Denmark in 2015. A mixed-mode response format allowed participants to respond via either the internet or telephone. The Danish National Statistics Bureau, Statistics Denmark, who also carried out the data collection, drew a random disproportional stratified sample of 4164 households. The disproportional sampling was carried out in order to improve the accuracy of the analysis, and it involved oversampling of households from the lowest income quintile, single-person and singleparent households. The oversampling helps to obtain more accurate estimates of population averages/proportions of the main measures (Hibberts et al 2012). To induce participation a prize draw was set up for people who responded. Adults (18 years or more, randomly selected from the household) were contacted by letter and first invited to respond to the questionnaire online. Reminders were sent out after two weeks, and individuals who did not respond online after this were contacted by telephone and invited to participate in a computer-assisted telephone interview if they preferred. The overall response rate was $45 \%$, varying from $29 \%$ for single parent families in the lowest income quintile and $59 \%$ for couples with income above this level and no children. The varying response rates in different strata are not surprising, as low-status groups are 
Final manuscript accepted for publication in Acta Sociologica. October 2018.

known to be less prone to participate in surveys. To account for the disproportional stratified sampling and non-response rates, data were weighted (adjusting to population prevalence regarding housing, education, region, income, and family type) in analyses where the whole sample was used (se later for details). Still, this does not guarantee that non-response bias is accounted for. We explored this risk further by comparing prevalence on some of the main measures in this study with prevalence observed in other studies. Judged by this comparison, the non-response issue appears to be very modest: (weighted) average life satisfaction in this study sample was 7.4 (95\% Cl 7.2-7.6) which is very similar to the 7.5 found in another Danish population survey carried out in 2015 (Statistics Denmark, 2015). The weighted proportion in this sample that ate a healthy and unhealthy diet, respectively, was $21.7 \%(95 \% \mathrm{Cl} 19.0-24.6)$ and $13.0 \%(95 \% \mathrm{Cl}$ 10.9-15.5). This is very similar to the proportions in a 2013 population survey of Danes where the same figures were $20.9 \%$ and $13.9 \%$ (Sundhedsstyrelsen, 2014).

\section{Measures}

Food budget pressure was measured on five levels. Based on a combination of question items respondents were categorized as food secure, moderately budget restricted, severely budget restricted, having low food security, or very low food security (the last two categories were renamed to accord with current terminology, as in earlier research they had been labelled food insecurity, and food insecurity with hunger (Bickel et al., 2000)). The first four levels have recently been shown to portray differences in responses to budget pressure in Danish households well (Nielsen et al., 2015), but additionally the present analysis allowed low and very low security to be separated. Two question items used in studies in New Zealand and the US, respectively measured the first three levels. Respondents were asked to state to what extent within the past 12 months 
Final manuscript accepted for publication in Acta Sociologica. October 2018.

the following statement was true: "I/We have been forced to buy cheaper food in order to be able to afford other things" (Salmond et al., 2005). A second item asked respondents to choose which statement best characterized the food they had eaten in the household during the past 12 months (Bickel et al., 2000). Reply options were: "We always have enough to eat and the kinds of food we want"; "we have enough to eat but not always the kinds of food we want"; "sometimes we don't have enough to eat"; and "often we don't have enough to eat". Respondents indicating that the first statement was untrue, and who used the first reply option in the second were categorized as food secure. Respondents who replied either 'very often' or 'sometimes' to the first question or did not confirm the first response in the second were moderately food restricted. Consumers who opted for both of these reply options were severely food restricted. To measure low and very low food insecurity we used the 6-item measure developed by the US Department of Agriculture which addresses degrees of inadequate access to food, both quantitatively and qualitatively (Bickel et al., 2000), (see also Lund et al., 2018 for details). Affirmative responses to the items produce total scores ranging from 0 to 6 . The measure enables the identification of low (score 2-4) and very low food security (score 5-6). Respondents qualifying in several categories were placed in the most severe category, and those qualifying in none were classified as food secure.

Adaptation of food practices. Measures of responses to restrained food budgets drew on a set of question items designed to catch adaptations in food practices pertaining to provisioning and kitchen practices, quality of food, and social aspects of eating practices. Items were constructed with the aim of including ways of adaptation that can be anticipated in not only low-income groups but broader population segments. Based on qualitative studies of food insecurity and coping practices (Dowler, 1997; Hamelin et al., 2002; Radimer et al., 1992), and of Danes experiencing food budget constraints (Nielsen and Holm, 2016), twelve question items were 
Final manuscript accepted for publication in Acta Sociologica. October 2018.

formulated asking respondents about the frequency of their adoption of a range of money-saving practices within the past 12 months (for details, see Results section). The response options were 'very often', 'often', 'sometimes', 'rarely', and 'never'. Most question items were tested in an earlier survey where they were used to distinguish between different general types of response to food budget pressure (Nielsen et al., 2015).

Life satisfaction. We measured life satisfaction through the Overall satisfaction with life single question item used in many international studies (Jeffrey et al., 2015). We asked the question "All things considered, how satisfied are you with your life nowadays?", and required respondents to rate their satisfaction on an 11-point scale with semantic anchor points ( $0=$ Very unsatisfied and 10=very satisfied). Applying cut-off points employed by EuroStat (EUROSTAT, 2015), we collapsed the scale into a binary variable indicating high (score 9-10) or low/moderate life satisfaction (0-8). Healthiness of food consumption. To measure this we employed Dietary Quality Score (DQS) (Toft et al., 2007). DQS is a simple measure focusing on four food components: fruit, vegetables, fish, and fats. It has been validated in the Danish context and is based on responses to eight food frequency questions, resulting in 0-9 scores through which food consumption (diets) can be categorized as unhealthy (scores 1-3), average (4-6), or healthy (7-9).

Socio-demographic background factors. From Statistics Denmark we extracted register data on gender, age (divided into four brackets), population density in the households' area (four categories), and household composition. As a measure of household purchasing power we used household equivalent disposable income, which was calculated by subtracting all publicly registered paid debts and taxes from the household's earnings, and adjusting the figures to account for number of household members according to OECD's modified equivalence scale 
Final manuscript accepted for publication in Acta Sociologica. October 2018.

(OECD, 2009). We divided household equivalent disposable income into five brackets ranging from OECD's relative poverty definition ( $50 \%$ below median) to the $9-10^{\text {th }}$ decile. As additional socioeconomic measures we included the main provider's income source, housing status (rental or owner), and highest completed educational level in the household.

\section{Analysis}

We first describe the distribution of the five food budget pressure categories categories across the socio-demographic factors. Unadjusted and adjusted tests of associations between the sociodemographic factors and each level of food budget pressure are also reported (using logistic regression). In adjusted analysis, all socio-demographic factors and response-modes (CATI or telephone) are inserted as control variables.

We report Spearman's rho correlation coefficients (which are recommended for ordinal level variables) in order to assess the association between level of food budget restriction and the outcome measures of interest: life satisfaction and healthiness of food consumption. To identify underlying patterns of adapting to food budget pressure, we conduct principal component analyses (PCAs) where 11 of the 12 items regarding responses to food budget restriction are input. We expected these 11 items to reflect and be reducible to four underlying types of adaptation (see Table 4 for details). The matrix input to the analysis is based on polychoric correlations, and for each component a Cronbach's alpha value is calculated (Gadermann et al., 2012). The $12^{\text {th }}$ item is not input to the component analysis, as this is the only item centering on a fifth strategy of relevance ('Less hospitality/socializing'). On basis of the PCA we calculated composite scales reflecting each type of adaptation (based on the item raw scores). All scales were rescaled to range from 0 to 100 so they are presented on a common metric. We display the extent to which 
Final manuscript accepted for publication in Acta Sociologica. October 2018.

adaptations take place in the budget-restricted households, and for each type of adaptation we report correlation coefficients (Spearman's rho, and tests of associations before and after adjustment for socio-demographic factors). Finally, we examine whether the types of adaptation are associated with high life satisfaction and unhealthy food consumption employing logistic regression. In analyses where the entire sample is featured (i.e. in Tables 1 and 2, and in supplementary Table 1) the weight variable described under 'Design of study' is employed. For details of the study sample, see additional material, Table 1.

\section{Results}

Table 1 shows how food security and different levels of food budget pressure relate to sociodemographic features of the population. Most of those sampled (66.2\%) were food secure, $17.7 \%$ were moderately budget restricted, $7.8 \%$ were severely budget restricted, and $6.0 \%$ and $2.4 \%$ had low and very low food security, respectively. These levels of food security are in line with earlier findings from Denmark (Borch and Kjærnes, 2016; Nielsen et al., 2015). The levels of low and very low food security here are lower than they are in the US, Canada and the UK (data are shown in supplementary Table 1; for more detailed discussion, see (Lund et al.,2018).

Table 1 here

The table shows that level of food budget pressure varies systematically with income. The prevalence of food security increases with higher income while the prevalence of all other categories of food budget pressure decrease with higher income. The prevalence of low food 
Final manuscript accepted for publication in Acta Sociologica. October 2018.

security and very low food security is highest among those with household incomes below the poverty line. Source of income (from employment, pensions or welfare benefits) is insignificant when other sociodemographic factors are controlled for (this reflects a close association with disposable income). Food budget pressure also varies significantly with household composition: Highest prevalence of food security is found among couples without children and lowest among single-parent households, whereas low and very low food insecurity as well as severe budget restriction is most prevalent among single parents. Educational background only varies significantly with low food security where it is more prevalent among people with the lowest educational levels. Variations according to gender and age are unsystematic. While more women appear to be severely budget restricted, very low food security is most prevalent among men and those aged 30-59 years. It is worth noticing that moderate food budget pressure is reported relatively evenly across all socio-demographic groups except the highest income group.

But what is the association between food budget pressure and life satisfaction and healthiness of food consumption? This is addressed in table 2.

Table 2 here

Table 2 shows clear, statistically significant associations between levels of food budget pressure and both outcomes. Degree of food budget pressure is negatively associated with life satisfaction and with healthy eating. High life satisfaction is systematically and negatively associated with level of food budget pressure, and is quite dramatically lower among those with low and, especially, very low food security. Thus, the incidence of high life satisfaction is very low among adults from households with very low food security. Still, the difference between other groups is quite 
Final manuscript accepted for publication in Acta Sociologica. October 2018.

considerable too. High life satisfaction in the severely budget restricted group is almost only half of that found among the food secure and mild budget restricted households. Post-hoc tests for differences in proportions show a clear statistical significant difference (food secure vs. severely budget restricted: $\mathrm{Chi}^{2} 37.8(1) ; \mathrm{p}<0.01$; mild budget restricted vs. severely budget restricted: $\mathrm{Chi}^{2}$ $17.5(1) ; p<0.05)$. In contrast, a post-hoc test shows no difference between the food secure and mild budget restricted households $\left(\mathrm{Chi}^{2} 37.8(1) ; \mathrm{p}=0.57\right)$. For dietary health, there is a marked difference between those with low and very low food security and the rest of the population, while differences between the food secure, and the moderately, and the severely budget restricted are small and unsystematic. The differential appears primarily with regard to prevalence of an unhealthy diet which adults with low and very low levels of food security are more than twice as likely to eat compared with those in the more secure groups.

We now analyze the ways people adapt to food budget restriction. Table 3 presents data showing the take-up of eleven specific practices by study participants. Food secure participants are omitted from this analysis.

Table 3 here

The table shows that the commonest adaptation relates to shopping, with participants purchasing foods either when they are on offer or from cheaper stores. This is followed by taking care to store and use leftovers, and substituting food with cheaper versions (conventional instead of organic foods, minced meats instead of whole cuts). More than half of the food budget pressured population reported acting in these ways often or very often. Making compromises on health, tastiness and variation in foods, and stretching the food were reported by between $21 \%$ and $48 \%$, 
Final manuscript accepted for publication in Acta Sociologica. October 2018.

and almost a third, made sure to invite fewer guests for meals in their homes. A much lower proportion of households (approximately 10\%) reported receiving food from family or friends as a form of help with their budgeting, or borrowing money to pay for foods.

Results from the PCA are also displayed in Table 3. Four factors were identified: 'Buying cheaper foods' (i.e. saving money during food provisioning), 'Compromising on food quality' (compromises on the quality, taste and variations in foods), 'Preparing frugal meals' (cooking and kitchen practices), and 'Depending on external help' (receiving food gifts or borrowing money to buy food). Scale means for the four derived factors showed that 'Buying cheaper foods' and 'Preparing frugal meals' were more widely adopted than 'Compromising on food quality' and, especially, 'Depending on external help'. The stand-alone measure of less hospitality/socializing is included as a fifth way of adapting to food budget pressure.

Next, we analyze how the five ways of adapting food practices relate to food budget pressure.

Table 4 here

Table 4 shows that all five ways of adapting food practices are positively associated with level of food budget pressure. The use of all ways of adapting increases with higher pressure. Adapting by 'Buying cheaper foods' and 'Preparing frugal meals' are used relatively frequently by the respondents experiencing food budget pressure, including the moderately budget restricted. 'Compromising on food quality' and 'Less hospitality/socializing' are only taken up by a minority of the moderately budget restricted (mean 30.2 and 25.9 , respectively) while they are used much more frequently by those with low or very low food security. 'Depending on external help' is 
Final manuscript accepted for publication in Acta Sociologica. October 2018.

hardly reported in the moderately and severely budget restricted groups, but occurs frequently in households with low food security (mean 30.0) and even more in those with very low food security (mean 52.6). In general, the correlation coefficients increase in tandem with the seriousness of the adaptations. 'Compromising on food quality' ( $r=0.491$ : 95\% Cl 0.437-0.542), 'Less hospitality/socializing' ( $r=0.520: 95 \% \mathrm{Cl} 0.459-0.570)$, and especially 'Depending on external help' ( $r=0.551: 95 \% \mathrm{Cl} 0.496-0.604)$ have stronger correlations with degree of food budget restriction than do Buying cheaper foods $(r=0.418$ : $95 \% \mathrm{Cl} 0.352-0.477)$ and 'Preparing frugal meals' $(r=0.311$ : $95 \% \mathrm{Cl} 0.242-0.374)$. This reveals, numerically speaking, that the more extreme adaptations are set in motion primarily when respondents are forced to adopt them by financial strain. All differences are significant also when controlling for socio-demographic factors, indicating that level of food budget pressure per se is decisive for the extent and type of adaptation embarked on.

Next, we analyze whether type of adaptation is associated with life satisfaction and dietary health when degree of food-budget restriction and socio-demographic factors are controlled for.

Table 5 here

The table shows that the adaptations of food practices relate to the two outcomes in different ways. First, going for foods with lower prices and cutting down on having guests are not important for neither life satisfaction nor healthiness of food consumption, as 'Buying cheaper foods' and 'Less hospitality/socializing' are not significantly associated with either of the outcomes. Changing kitchen practices in terms of 'Preparing more frugal meals' appears to be linked with more healthy food consumption and leave life satisfaction unaffected, while making changes that are entail 
Final manuscript accepted for publication in Acta Sociologica. October 2018.

'Compromising on food quality' are negative both for life satisfaction and healthiness of food consumption. Surprisingly, 'Depending on external help' increases the probability of having high life satisfaction.

\section{Discussion}

In this article, we present the first study of the ways in which food budget pressure relates to dietary health and quality of life in an affluent population. Using data from a representative survey of Danish households we show that also in the Scandinavian welfare society Denmark food budget pressure and food insecurity exist and are associated with negative impact on life satisfaction and health. In Denmark, food budget pressure varies first of all with income and household composition, and we confirm findings from a US based study, that those facing severe food budget restriction share socio-economic conditions with those facing low and very low food security (Coleman-Jensen, 2010). In addition, we find that life satisfation is markedly lower not only in households with low and very low food security, but also in those with severe food budget restrictions. For dietary health, however, only the groups with low and very low food security have markedly higher frequency of unhealthy food consumption. In an affluent population as the Danish, then, financial pressure on food budgets appears to affect life satisfaction at an earlier stage than healthiness of food consumption. Still, the results suggest that more modest forms of food budget restriction may have negative outcomes.

We identified five ways of adapting food consumption to budget pressure, which are parallel to those reported in studies of food insecurity from other countries (Alkon et al., 2013; Burns et al., 2013; Dowler, 1997; Pfeiffer et al., 2011). Our analysis shows that while 'Preparing frugal meals' 
Final manuscript accepted for publication in Acta Sociologica. October 2018.

was positively associated with healthy food consumption 'Compromising on food quality' were negatively so. This suggests that the idea based on theoretical modelling, namely that healthy dietary recommendations and low costs can readily be accommodated the same time (Parlesak et al., 2016; Saxe, 2011), needs to be moderated, as real-life adaptations of food consumption practices are diverse. The contrasting association to dietary health may reflect the substantive nature of the two ways of adapting food consumption practices. 'Compromising on food quality' involves altering composition of food consumption in a less healthy direction. This mirrors findings from other countries linking food insecurity to less fruit and vegetables, and to higher intake of cheap, energy-dense foods (Leung et al., 2017). It also echoes a Danish longitudinal study showing that, in the long run, unemployment leads to replacement of fresh and animal-based foods by carbohydrate- and sugar-rich foods (Smed et al., 2018). Preparing frugal meals, by contrast, probably supports the maintenance of existing eating habits, in the sense that more efficient kitchen practices (e.g. using left-overs) make it unnecessary to switch to cheaper, and less healthy foods.

It is surprising that 'Buying cheaper foods' and 'Less hospitality/socializing' were not associated with life satisfaction as meals are cornerstones in social life and central to conceptions of 'the good life'. However, life satisfaction not only depends on food, and the very strong association with food budget pressure could then be reflections of other hardships with food budget pressure than those related to food per se. Likewise, it was somewhat surprising to find that 'Depending on external help' was associated with high life satisfaction. This suggests that in Denmark gifts of food and loans of money for food tend to take place within social networks and personal relationships, rather than in transactions with charitable institutions, as described in other countries (Kaiser and Hermsen, 2015; Lambie-Mumford and Dowler, 2014). 
Final manuscript accepted for publication in Acta Sociologica. October 2018.

We found that type and degree of adaptation depended on level of restriction per se. A sequence, or cascade, of adaptions were at work here, with changes in food quality, hospitality and seeking external help being made only when adjustments to food provisioning and kitchen practices were proving to be insufficient adaptations. A recent summary of qualitative studies from other countries has pointed to a sequence of just this kind (Lambie-Mumford et al., 2014) and a few quantitative surveys display sequences in how adaptations are taken up. A Danish survey had similar results to ours, (Nielsen et al., 2015) while two US studies among low and very low income groups showed sequences in people's reliance on more, and increasingly distant, personal relations for gifts and loans for food (Kaiser and Hermsen, 2015) and in the adoption of an increasing number of hunger-coping strategies (Pinard et al., 2016).

In an affluent state as Denmark, specific adaptations to budget pressure thus differ from those taken up in less affluent groups. Still, it is noteworthy, that in our study a proportion even of the moderately and severely budget restricted respondents reported limiting meal invitations to guests and 'Compromising on food quality'. Thus, even before reaching the point of low or very low food security, people seem, to some extent, to be making changes, which influence their social life and the quality of their food. This confirms the relevance of studying how people in affluent groups adapt to food budget pressure (Ashby et al., 2016).

We have contributed to existing research with the first nationally representative survey of adaptation to food budget pressure in a social-democratic Scandinavian welfare state. We have shown that even in an affluent country with a universal welfare system, food budget pressure and food insecurity are negatively associated with life satisfaction and dietary health. Our results have implications for policy and research. 
Final manuscript accepted for publication in Acta Sociologica. October 2018.

Firstly, our results critique the idea, which is dominant in Danish debate and policy, that unhealthy food consumption is caused by cultural factors in terms of low educational background. Instead, our results show that material circumstances in terms of income and household structure are decisive for the pressure on food budgets people experience and its negative consequences. For public authorities in Denmark this points to a need to address more directly structural factors in public health policy. It also underlines the need for the continuous monitoring of the Danish populations' diet which has taken place since 1985 (Pedersen et al., 2015) to start paying special attention to issues of food budget pressure and food insecurity. For sociological poverty research, our study highlights the relevance of a special focus on food consumption. First, responses to food insecurity may entail a less healthy diet, and this has relevance for health inequality. This aspect should be central when analyzing consequences of deprivation. Further, food consumption practices intersect with multiple other daily practices that are central for daily life and life satisfaction. It is therefore one avenue to study in more detail the impact of poverty and deprivation on social interaction, family life, identity and wellbeing. But food is also a basic and absolute physiological need. In research, poverty and deprivation are relative phenomena related to the resources needed to obtain the living condition which is customary in their society (Lister, 2004). A focus on food consumption may highlight how even in affluent societies deprivation promotes practices which fail to fulfill basic needs.

It is a limitation of this study that it is cross-sectional, and therefore does not throw light on causality. Our findings testify to developments over time, which we cannot document with the present study design, so longitudinal studies that examine the combined trajectories and influences between budget pressure, adaptions and adverse outcomes are important to initiate. Further research is also necessary to gain more knowledge about how materials, meanings and 
Final manuscript accepted for publication in Acta Sociologica. October 2018.

competences are involved in adaptation of food consumption practices following food budget pressure. The response rate of the survey was comparatively lower than typical population-based surveys carried out by Statistics Denmark. This is because of the disproportional sampling design where low-income, single-adult, and single parent households were oversampled. While, we cannot rule out non-response bias we registered only minor differences between this study and other Danish data sources regarding prevalence of healthiness/unhealthiness of food eaten, and levels of life satisfaction.

\section{Funding}

This research was supported by the Danish Strategic Research Council (Grant number: 060300450B)

\section{Declaration of conflicting interests}

The Authors declare that there is no conflict of interest.

\section{Acknowledgements}

The authors wish to thank Sinne Smed, IFRO, University of Copenhagen, and the following members of the project's scientific advisory board for substantial contributions to the study's design and analysis: John Barrett, Leeds University, UK; Elizabeth Dowler, University of Warwick, UK; Arne Dulsrud, SIFO/HiOA, Norway; Christine Olson, Cornell University, USA; Sabine Pfeiffer, ISF Munich, Germany; Dale Southerton, Manchester University, UK; Inge Tetens, DTU, Denmark; David Watson, PlanMiljø, Veks $\varnothing$, Denmark.

\section{References}

Alkon AH, Block D, Moore K et al. (2013) Foodways of the urban poor. Geoforum 48: 126-135. 
Final manuscript accepted for publication in Acta Sociologica. October 2018.

Ashby S, Kleve S, McKechnie R et al. (2016) Measurement of the dimensions of food insecurity in developed countries: a systematic literature review. Public Health Nutrition 19(16): 2887-2896.

Bates B, Roberts C, Lepps H et al. (2017) The Food \& You Survey Wave 4. Combined Report for England, Wales, and Northern Ireland. London: Food Standards Agency.

Bickel G, Nord M, C P et al. (2000) Guide to Measuring Household Food Secruity. Alexandria: United States Department of Agriculture, Food and Nutrition Service.

Bocquier A, Vieux F, Lioret S et al. (2015) Socio-economic characteristics, living conditions and diet quality are associated with food insecurity in France. Public Health Nutrition 18(16): 2952-2961.

Borch A and Kjærnes U (2016) The Prevalence and Risk of Food Insecurity in the Nordic Region: Preliminary Results. Journal of Consumer Policy, Journal of Consumer Policy 39(2): 261-274.

Burns C, Cook K and Mavoa H (2013) Role of expendable income and price in food choice by low income families. Appetite 71: 209-217.

Canvin K, Marttila A, Burstrom B et al. (2009) Tales of the unexpected? Hidden resilience in poor households in Britain. Social Science and Medicine 69(2): 238-245.

Coleman-Jensen A (2010) US Food Insecurity Status: Toward a Refined Definition. Social Indicators Research 95(2): 215-230.

Coleman-Jensen A, Rabbitt MP and Gregory CA (2016) Household Food Security in the United States in 2015, ERR-215. Washington: United States Department of Agriculture.

Csikszentmihalyi M (1997) Living well. The Psychology of Everyday Life. London: Phoenix, Orion Books Itd. 
Final manuscript accepted for publication in Acta Sociologica. October 2018.

Csikszentmihalyi M and Hunter J (2003) Happiness in everyday life: The uses of experience sampling. Journal of Happiness Studies 4: 185-199.

Darmon N and Drewnowski A (2008) Does social class predict diet quality? The American journal of clinical nutrition 87(5): 1107-17.

Devine CM, Jastran M, Jabs J et al. (2006) 'A lot of sacrifices:' work-family spillover and the food choice coping strategies of low-wage employed parents. Social Science \& Medicine 63(10): 2591603.

Dowler E (1997) Budgeting for food on a low income in the UK: the case of lone-parent families. Food Policy 22(5): 405-417.

Dowler EA and O'Connor D (2012) Rights-based approaches to addressing food poverty and food insecurity in Ireland and UK. Social Science and Medicine, 74(1): 44-51.

Esping-Andersen G (1990) The Three Worlds of Welfare Capitalism. Cambridge: Polity Press.

EUROSTAT (2015) Quality of life in Europe - facts and views - overall life satisfaction - Statistics Explained. Available at: $\underline{\text { http://ec.europa.eu/eurostat/statistics- }}$

explained/index.php/Quality of life in Europe - facts and views - overall life satisfaction (accessed 14 November 2017)

Eurostat (2016) Material deprivation statistics - financial stress and lack of durables. Statistics Explained. Available from: http: // ec. europa. eu/ eurostat/ statistics-explained/ index. php/ Material_deprivation statisticsfocusedonageandgenderdifferences (accessed 3 April 2018). 
Final manuscript accepted for publication in Acta Sociologica. October 2018.

Folkman S, Lazarus RS, Dunkel-Schetter C et al. (1986) Dynamics of a stressful encounter: cognitive appraisal, coping, and encounter outcomes. Journal of personality and social psychology 50(5): 992-1003.

Fødevarestyrelsen, Advisory Board for mad måltider og sundhed. (2018) Anbefalinger til regeringen og en invitation til hele Danmark. København: Fødevarestyrelsen.

Groth M V, Fagt S and Brøndsted L (2001) Social determinants of dietary habits in Denmark. European Journal of Clinical Nutrition 55: 959-966.

Gundersen C and Ziliak JP (2015) Food insecurity and health outcomes. Health Affairs 34(11): 1830-1839.

Hadley C and Crooks DL (2012) Coping and the Biosocial Consequences of Food Insecurity in the 21st Century. Yearbook of Physical Anthropology, 94: 72-94.

Halkier B, Katz-Gerro T and Martens L (2011) Applying practice theory to the study of consumption: Theoretical and methodological considerations. Journal of Consumer Culture 11(1): 3-13.

Hamelin AM, Beaudry M, Habicht JP (2002). Characterization of household food insecurity in Quebec: food and feelings. Social Science \& Medicine 54: 119-132.

Heflin CM, Siefert K and Williams DR (2005) Food insufficiency and women's mental health: Findings from a 3-year panel of welfare recipients. Social Science and Medicine 61(9): 1971-1982. Hibberts M, Johnson R, Hudson K (2012). Common survey sampling techniques. In (Ed: Gideon L.). Handbook of Survey Methodology for the Social Sciences, New York: Springer p53-74 
Final manuscript accepted for publication in Acta Sociologica. October 2018.

Hobfoll SE (2010) Conservation of Resources Theory: Its Implicatin for Stress, Health, and Resilience. In: Folkman S (ed.), The Oxford handbook of Stress, Health, and Coping, Oxford: Oxford University Press, pp. 127-147.

Holm, L. 2013, The sociology of Food Consumption, in Murcott, A. Belasco, W. \& Jackson, P. (eds) The Handbook of Food Research, London: Berg Publishers. 324-337.

Jeffrey K, Abdala S and Quick A (2015) European' social and personal wellbeing. Topline results from round 6 of the European Social Survey. London: City University London.

Jones NR V, Conklin Al, Suhrcke M et al. (2014) The growing price gap between more and less healthy foods: Analysis of a novel longitudinal UK dataset. PLOS ONE 9(10) e109343.

Kaiser M and Hermsen J (2015) Food Acquisition Strategies, Food Security, and Health Status Among Families With Children Using Food Pantries. Families in Society: The Journal of Contemporary Social Services 96(2): 83-90.

Kempson KM, Keenan DP, Sadani PS et al. (2002) Food management practices used by people with limited resources to maintain food sufficiency as reported by nutrition educators. Journal of the American Dietetic Association 102(12): 1795-1799.

Kneafsey M, Dowler E, Lambie-Mumford H et al. (2013) Consumers and food security: Uncertain or empowered? Journal of Rural Studies, 29(2013): 101-112.

Koch MB, Davidsen M and Juel K (2012) Social ulighed i sundhed, sygelighed og trivsel 2010, og udviklingen siden 1987 [Social inequality, morbidity and wellbeing 2010, development since 1987]. Copenhagen: Statens Institut for Folkesundhed, SDU. 
Final manuscript accepted for publication in Acta Sociologica. October 2018.

Krueger AB, Kahneman D, Fischler C, et al. (2009) Time use and subjective well-being in France and the U.S. Social Indicators Research 93(1): 7-18.

Lambie-Mumford H and Dowler E (2014) Rising use of 'food aid' in the United Kingdom. British Food Journal 116(9): 1418-1425.

Lambie-Mumford H, Crossley D, Jensen E et al. (2014) Household Food Security in the UK: A Review of Food Aid. Sheffield: University of Sheffield and Food Ethics Council.

Leung CW, Mph S, Epel ES et al. (2017) Food Insecurity Is Inversely Associated with Diet Quality of Lower-Income Adults. Journal of the Academy of Nutrition and Dietetics, 114(12): 1943-1953.

Lister R (2004) Poverty. Cambridge: Polity Press.

Lund TB, Holm L, Tetens I et al. (2018) Food insecurity in Denmark - Socio-demographic determinants and associations with eating- and health-related variables. European Journal of Public Health 28(2): 283-88.

Nielsen A and Holm L (2016) Making the most of less. Food, Culture \& Society 19(1): 71-91.

Nielsen A, Lund TB and Holm L (2015) The Taste of 'the End of the Month', and How to Avoid It: Coping with Restrained Food Budgets in a Scandinavian Welfare State Context. Social Policy and Society 14(3): 429-442.

Nolan M, Rikard-Bell G, Mohsin M et al. (2006) Food insecurity in three socially disadvantaged localities in Sydney, Australia. Health promotion Journal of Australia 17(3): 247-54.

OECD (2009) What are Equivalence Scales. http://www.oecd.org/eco/growth/OECDNote EquivaleneScales.pdf. Accessed October 232018. 
Final manuscript accepted for publication in Acta Sociologica. October 2018.

OECD (2017) OECD Income Distribution Database (IDD): Gini, poverty, income, Methods and Concepts. Social and welfare issues. Available from: http://www.oecd.org/social/incomedistribution-database.htm (accessed 5 October 2017).

Parlesak A, Tetens I, Jensen JD et al. (2016) Use of linear programming to develop cost-minimized nutritionally adequate health promoting food baskets. PLOS ONE 11(10) e016411.

Pedersen AN, Christensen T, Matthiessen J et al. (2015) Danskernes Kostvaner 2011-2013. Hovedresultater. Søborg, DTU Fødevareinstituttet.

Pfeiffer S, Ritter T and Hirseland A (2011) Hunger and nutritional poverty in Germany: quantitative and qualitative empirical insights. Critical Public Health 21(4): 417-428.

Pinard C, Smith TM, Calloway EE et al. (2016) Auxiliary measures to assess factors related to food insecurity: Preliminary testing and baseline characteristics of newly designed hunger-coping scales. Preventive Medicine Reports, 4: 289-295.

Purdam K, Garrat E, Esmail A (2016). Hungry? Food insecurity, social stigma and embarrassment in the UK. Sociology, 50(6): 1072-1088.

Radimer KL, Olson CM, Greene JC et al. (1992) Understanding hunger and developing indicators to assess it in women and children. Journal of Nutrition Education 24(1): 36S-44S.

Saxe H (2011) Diet as a healthy and cost-effective instrument in environmental protection. In: Nriagu JO (ed.) Encyclopedia of Environmental Health, Amsterdam: Elsevier, pp. 70-82. 
Final manuscript accepted for publication in Acta Sociologica. October 2018.

Simmet A, Depa J, Tinnemann P et al. (2017) The Dietary Quality of Food Pantry Users:

A Systematic Review of Existing Literature. Journal of the Academy of Nutrition and Dietetics, 117(4): 563-576.

Smed S, Tetens I, Lund TB et al. (2018) The consequences of unempmloyment on diet composition and purchase behaviour - A longitudinal study from Denmark. Public Health Nutrition 21(3): 580592.

Sundhedsstyrelsen (2018) Danskernes Sundhed - Den Nationale Sundhedsprofil 2017 [National health profile, Denmark 2017]. København: Sundhedsstyrelsen.

Tarasuk V, Maclean H (1990). The food problems of low income single mothers: an ethnographic study. Canadian Home Economics Journal 40:76-81.

Tarasuk V, Mitchel A and Dachner N (2014) Household Food Insecurity in Canada 2012. Toronto: PROOF.

Toft U, Kristoffersen L, Lau C et al. (2007) The Dietary Quality Score: validation and association with cardiovascular risk factors: the Inter99 study. European Journal of Clinical Nutrition 61(2): $270-278$.

Vallgårda S (2011) Addressing individual behaviours and living conditions: four Nordic public health policies. Scandinavian journal of public health 39(6 Suppl): 6-10.

Warde A (2013) What sort of practice is eating? In: Shove, E. and Spurling, N (eds) Sustainable Practices: Social Theory and Climate Change, Oxon: Routledge, p. 221.

Warde A (2016) The Practice of Eating. Cambridge: Polity. 
Final manuscript accepted for publication in Acta Sociologica. October 2018.

Whitaker RC, Phillips SM and Orzol SM (2006) Food Insecurity and the Risks of Depression and Anxiety in Mothers and Behavior Problems in their Preschool-Aged Children. Pediatrics 118(3): e859-e868. 
Final manuscript accepted for publication in Acta Sociologica. October 2018.

Table 1. Prevalence of food security, moderate budget restriction, severe budget restriction, low food security and very low food security across socio-demographic characteristics $(n=1877)$ - unadjusted and adjusted $p$-values ${ }^{A}$

\begin{tabular}{|c|c|c|c|c|c|c|c|c|c|c|}
\hline & \multicolumn{2}{|c|}{ Food secure } & \multicolumn{2}{|c|}{$\begin{array}{l}\text { Moderately } \\
\text { budget } \\
\text { restricted }\end{array}$} & \multicolumn{2}{|c|}{$\begin{array}{l}\text { Severely budget } \\
\text { restricted }\end{array}$} & \multicolumn{2}{|c|}{$\begin{array}{l}\text { Low food } \\
\text { security }\end{array}$} & \multicolumn{2}{|c|}{$\begin{array}{l}\text { Very low food } \\
\text { security }\end{array}$} \\
\hline & $\%$ & $\begin{array}{l}\text { Unadjusted/Adj } \\
\text { usted }\end{array}$ & $\%$ & $\begin{array}{l}\text { Unadjuste/ } \\
\text { Adjusted }\end{array}$ & $\%$ & $\begin{array}{l}\text { Unadjusted/Adju } \\
\text { sted }\end{array}$ & $\%$ & $\begin{array}{l}\text { Unadjusted/A } \\
\text { djusted }\end{array}$ & $\%$ & $\begin{array}{l}\text { Unadjuste/A } \\
\text { djusted }\end{array}$ \\
\hline & & $p$-values & & $\mathrm{p}$-values & & $\mathrm{p}$-values & & $\mathrm{p}$-values & & $p$-values \\
\hline \multicolumn{11}{|l|}{ Gender } \\
\hline Woman & 63.9 & n.s/n.s & 18.7 & n.s/n.s & 9.9 & $<0.01 /<0.01$ & 6.0 & n.s/n.s & 1.6 & n.s $/<0.05$ \\
\hline Man & 68.8 & & 16.6 & & 5.4 & & 5.9 & & 3.4 & \\
\hline \multicolumn{11}{|l|}{ Age } \\
\hline $18-29$ years & 45.7 & $<0.0001 /$ n.s. & 27.0 & n.s/n.s & 14.1 & $<0.01 /$ n.s. & 11.7 & $<0.05 /$ n.s. & 1.5 & $<0.01 /<0.0001$ \\
\hline $30-44$ years & 58.1 & & 20.4 & & 10.6 & & 6.8 & & 4.1 & \\
\hline $45-59$ years & 63.9 & & 17.0 & & 7.8 & & 7.3 & & 4.0 & \\
\hline 60 years + & 76.5 & & 14.8 & & 4.8 & & 3.4 & & 0.5 & \\
\hline \multicolumn{11}{|l|}{ Family type } \\
\hline $\begin{array}{l}\text { Couple without } \\
\text { children }\end{array}$ & 73.9 & $<0.0001 /<0.05$ & 18.1 & n.s/n.s & 4.2 & $<0.01 /$ n.s. & 2.3 & $<0.001 /<0.05$ & 1.5 & $<0.01 /$ n.s. \\
\hline Couple with children & 62.2 & & 20.7 & & 9.7 & & 6.8 & & 0.7 & \\
\hline Lives alone & 63.8 & & 14.4 & & 9.3 & & 8.3 & & 4.2 & \\
\hline Single-parent & 39.3 & & 18.6 & & 16.6 & & 16.8 & & 8.7 & \\
\hline \multicolumn{11}{|l|}{ Housing } \\
\hline Owns house/flat & 72.6 & $<0.0001 /$ n.s. & 16.8 & n.s/n.s & 6.4 & n.s/n.s & 3.9 & $<0.05 /$ n.s. & 0.3 & $<0.0001 /<0.05$ \\
\hline Rents house/flat & 57.6 & & 18.9 & & 10.0 & & 8.7 & & 5.2 & \\
\hline \multicolumn{11}{|l|}{ Source of income } \\
\hline $\begin{array}{l}\text { Employment (including } \\
\text { self-employed, } \\
\text { student) }\end{array}$ & 63.7 & $<0.001 /$ n.s. & 19.7 & n.s/n.s & 8.6 & n.s/n.s & 6.3 & $<0.0001 /$ n.s. & 2.1 & $<0.0001 /$ n.s. \\
\hline Welfare benefit & 54.5 & & 6.3 & & 6.7 & & 21.2 & & 11.3 & \\
\hline Disability pension & 52.9 & & 5.5 & & 10.5 & & 20.3 & & 10.9 & \\
\hline
\end{tabular}


Final manuscript accepted for publication in Acta Sociologica. October 2018.

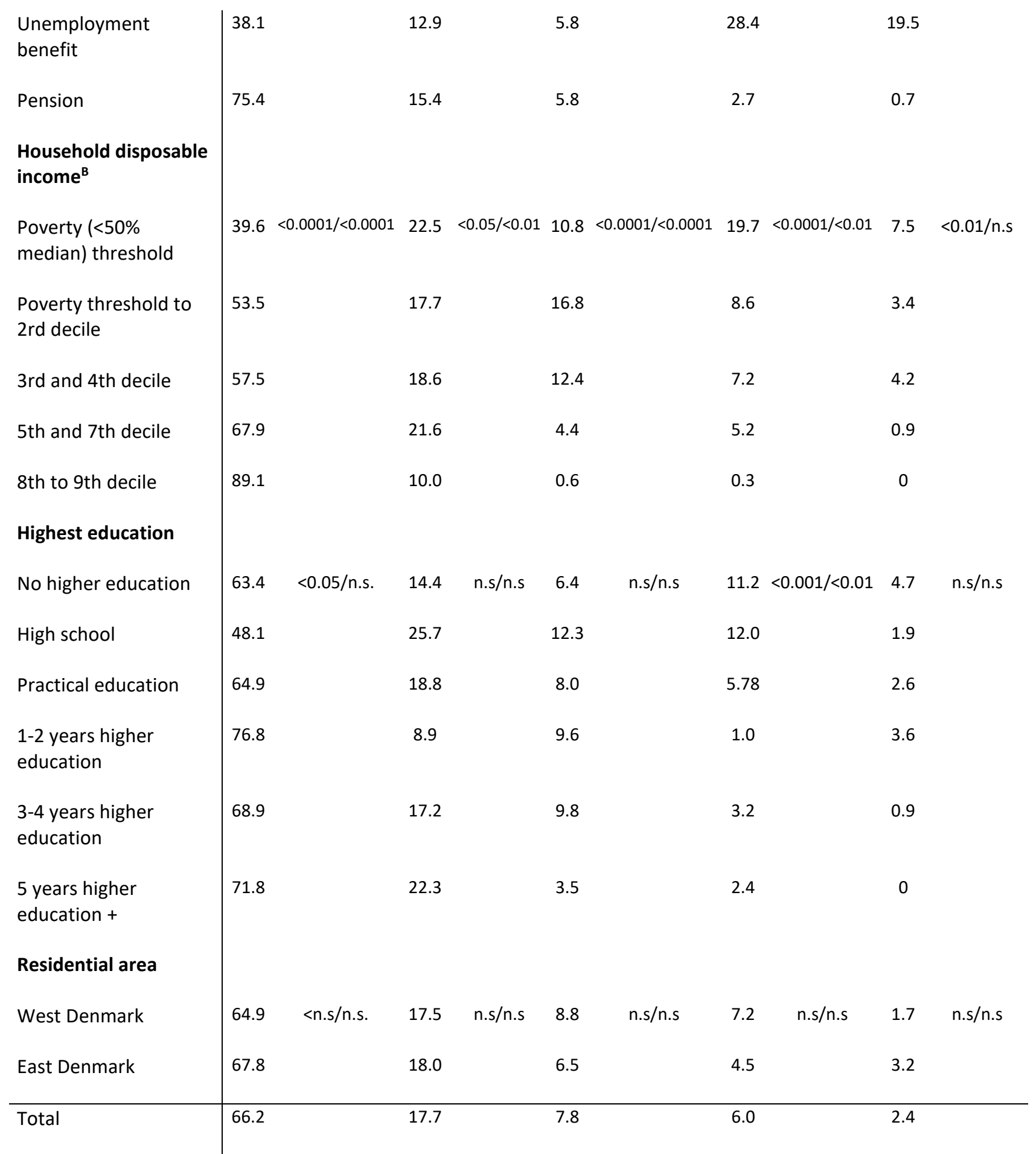

Notes: A: Controls include all socio-demographic factors reported in the table (input as factorial variables).

B: Poverty (<50\% median) threshold: <113350 DKK; Poverty threshold to 2rd decile:113.350-155.735 DKK; 3rd and 4th decile:155.735-226.684 DKK; 5th and 7th decile: 226.684-322.871 DKK; 8th to 9th decile: $>322.871$ DKK. 
Final manuscript accepted for publication in Acta Sociologica. October 2018.

Table 2. Degree of food budget, Dietary Quality Score and Life satisfaction

\begin{tabular}{|c|c|c|c|c|c|c|}
\hline & $\begin{array}{l}\text { Food } \\
\text { secure }\end{array}$ & $\begin{array}{l}\text { Moderately } \\
\text { budget } \\
\text { restricted }\end{array}$ & $\begin{array}{l}\text { Severely } \\
\text { budget } \\
\text { restricted }\end{array}$ & $\begin{array}{l}\text { Low food } \\
\text { security }\end{array}$ & $\begin{array}{l}\text { Very low food } \\
\text { security }\end{array}$ & Test statistics \\
\hline \multicolumn{7}{|l|}{ Dietary quality score } \\
\hline Unhealthy diet (\%) & 10 & 8 & 11 & 26 & 35 & \\
\hline Medium (\%) & 68 & 74 & 70 & 62 & 58 & \\
\hline Healthy diet (\%) & 22 & 18 & 19 & 12 & 8 & $\begin{array}{l}\text { Spearman's rho }-0.138 \\
\quad N=1867 ; p<0.001\end{array}$ \\
\hline \multicolumn{7}{|c|}{ High life satisfaction (\%) } \\
\hline & 44 & 38 & 22 & 11 & 4 & $\begin{array}{l}\text { Spearman's rho }-0.252 \\
N=1877 ; p<0.001\end{array}$ \\
\hline
\end{tabular}


Final manuscript accepted for publication in Acta Sociologica. October 2018.

Table 3. Details, and principal component analysis, of 11 questions about food-related adaptation to budget pressure ${ }^{A}$ among Danes who are food budget restricted ( $N=752$ )

\begin{tabular}{|c|c|c|c|c|c|}
\hline & \multirow[b]{2}{*}{$\operatorname{Mean}^{\mathrm{B}} / \%^{\mathrm{C}}$} & \multicolumn{4}{|c|}{ Results from principal component analysis ${ }^{D}$} \\
\hline & & $\begin{array}{l}\text { Buying } \\
\text { cheaper } \\
\text { foods }\end{array}$ & $\begin{array}{l}\text { Preparing } \\
\text { frugal meals }\end{array}$ & $\begin{array}{l}\text { Compromising } \\
\text { on food } \\
\text { quality }\end{array}$ & $\begin{array}{l}\text { Depending } \\
\text { on external } \\
\text { help }\end{array}$ \\
\hline Shopped in cheaper places than usual & $3.2 / 79.0$ & 0.55 & & & \\
\hline Purchased more products on offer & $3.3 / 83.8$ & 0.52 & & & \\
\hline $\begin{array}{l}\text { Purchased minced meat instead of whole } \\
\text { cuts }\end{array}$ & $2.6 / 58.6$ & 0.39 & & & \\
\hline Avoided purchasing organic foods & $2.8 / 64.4$ & 0.49 & & & \\
\hline Took care to store and use leftovers & $3.1 / 76.1$ & & 0.70 & & \\
\hline Stretched the food to make it last longer & $2.4 / 48.1$ & & 0.70 & & \\
\hline $\begin{array}{l}\text { Made compromises regarding the } \\
\text { healthiness of the food }\end{array}$ & $1.8 / 29.1$ & & & 0.53 & \\
\hline $\begin{array}{l}\text { Made compromises regarding the } \\
\text { variation of foods and dishes }\end{array}$ & $2.0 / 35.5$ & & & 0.54 & \\
\hline $\begin{array}{l}\text { Made compromises regarding the } \\
\text { tastiness of foods and dishes }\end{array}$ & $1.5 / 21.3$ & & & 0.61 & \\
\hline $\begin{array}{l}\text { Received food products from family, } \\
\text { friends or others in order to help on a } \\
\text { stretched budget }\end{array}$ & $0.8 / 9.7$ & & & & 0.69 \\
\hline $\begin{array}{l}\text { Borrowed money (e.g. from friends or } \\
\text { family) to make sure that there was } \\
\text { enough food at the end of the month }\end{array}$ & $0.7 / 9.6$ & & & & 0.72 \\
\hline $\begin{array}{l}\text { I made sure to invite fewer guests over } \\
\text { to eat in our home }\end{array}$ & $1.8 / 32.4$ & & & & \\
\hline Scale mean (s.d.)E/ & $45.5(34.4)$ & $74.6(21.5) /$ & $68.4(24.9) /$ & $44.0(26.2) /$ & $19.1(24.9) /$ \\
\hline Cronbach's alphaF & & 0.82 & 0.86 & 0.77 & 0.78 \\
\hline $\begin{array}{l}\text { A For all question items, respondents were instr } \\
\text { in question had been employed. Five response }\end{array}$ & $\begin{array}{l}\text { ucted to think al } \\
\text { pptions were off }\end{array}$ & $\begin{array}{l}\text { bout the last } 12 \\
\text { ered: } 0=\text { Never, }\end{array}$ & $\begin{array}{l}2 \text { months and aske } \\
1=\text { Seldom, } 2=\text { Son }\end{array}$ & $\begin{array}{l}\text { ed to report how ofte } \\
\text { netimes, } 2=\text { Often, } 4=\end{array}$ & $\begin{array}{l}\text { the strategy } \\
\text { ery often. }\end{array}$ \\
\hline
\end{tabular}


Final manuscript accepted for publication in Acta Sociologica. October 2018.

\footnotetext{
C Percentage responding "often" or "very often"

D Polychoric correlation matrix was used as input to the principal component analysis. Factor loadings from oblimin rotation are reported (loadings $<0.20$ are suppressed).

${ }^{E}$ All scales of ways of adapting are composites based on raw scores of the items that load highly on the dimension. The raw scores were rescaled to range from 0-100.

F Cronbach's alpha calculated using the formula: $\left(\mathrm{k}^{*} r_{\text {avg }}\right) /\left(1+(\mathrm{k}-1)^{*} r_{\text {avg }}\right)$, where $\mathrm{k}$ is number of items and $r_{\text {avg }}$ is the average of all polychoric correlations of the particular scale (Gadermann et al 2012).

G This was a stand-alone measure of less hospitality / socializing. Therefore, it was not used in the principal component analysis.
} 
Final manuscript accepted for publication in Acta Sociologica. October 2018.

Table 4. The use of five coping strategies by four food budget pressure groups - Spearman's correlation coefficients with $95 \% \mathrm{Cl}$ intervals ${ }^{\mathrm{A}}$ tests of association before and after adjustment for socio-demographic variables ${ }^{A}$

$\begin{array}{ccccc}\begin{array}{c}\text { Buying cheaper } \\ \text { foods }\end{array} & \begin{array}{c}\text { Preparing frugal } \\ \text { meals }\end{array} & \begin{array}{c}\text { Compromising on food } \\ \text { quality }\end{array} & \text { Less } & \text { Depending on external } \\ \text { help }\end{array}$

Means (sd.) Means (sd.) Means (sd.) Means (sd.) Means (sd.)

\begin{tabular}{|c|c|c|c|c|c|c|c|c|c|c|}
\hline \multicolumn{11}{|l|}{ Degree of food budget restriction } \\
\hline Moderately budget restricted & 64.3 & $(21.0)$ & 59.3 & $(25.2)$ & 30.2 & (19.7) & 25.9 & $(26.1)$ & 6.1 & $(12.8)$ \\
\hline Severely budget restricted & 75.1 & $(20.4)$ & 68.3 & (22.9) & 40.3 & $(24.2)$ & 42.9 & (31.5) & 12.7 & $(16.5)$ \\
\hline Low food security & 81.3 & $(18.9)$ & 72.5 & $(25.2)$ & 54.3 & $(23.0)$ & 59.7 & $(32.4)$ & 30.0 & $(25.3)$ \\
\hline Very low food security & 88.7 & $(17.5)$ & 85.0 & $(18.7)$ & 73.2 & $(24.0)$ & 82.1 & $(24.8)$ & 52.6 & (31.7) \\
\hline Spearman's correlation & \multicolumn{2}{|c|}{0.418} & \multicolumn{2}{|c|}{0.311} & \multicolumn{2}{|c|}{0.491} & \multicolumn{2}{|c|}{0.520} & \multicolumn{2}{|c|}{0.551} \\
\hline $95 \% \mathrm{Cl}$ Intervals & \multicolumn{2}{|c|}{$0.352-0.477$} & \multicolumn{2}{|c|}{$0.242-0.374$} & \multicolumn{2}{|c|}{$0.437-0.542$} & \multicolumn{2}{|c|}{$0.459-0.570$} & \multicolumn{2}{|c|}{$0.496-0.604$} \\
\hline Unadjusted / adjusted test of association & \multicolumn{2}{|c|}{$<0.001 /<0.001$} & \multicolumn{2}{|c|}{$<0.001 /<0.001$} & \multicolumn{2}{|c|}{$<0.001 /<0.001$} & \multicolumn{2}{|c|}{$<0.001 /<0.001$} & \multicolumn{2}{|c|}{$<0.001 /<0.001$} \\
\hline \multicolumn{11}{|c|}{$\begin{array}{l}\text { A Bias-corrected confidence intervals were calculated using bootstrapping (1000 replications) in Stata. Only observations where there were no missing values regarding } \\
\text { the coping strategies were used in this analysis }(\mathrm{N}=752) \text {. }\end{array}$} \\
\hline
\end{tabular}


Final manuscript accepted for publication in Acta Sociologica. October 2018.

Table 5. Associations between ways of adapting food consumption and high life satisfaction and unhealthy diet

\begin{tabular}{|c|c|c|c|c|c|c|}
\hline \multirow[b]{2}{*}{ Ways of adapting } & \multicolumn{3}{|c|}{$\begin{array}{l}\text { High life satisfaction } \\
(\mathrm{N}=752)^{\mathrm{a}}\end{array}$} & \multicolumn{3}{|c|}{$\begin{array}{l}\text { Unhealthy diet } \\
(\mathrm{N}=752)^{\mathrm{a}}\end{array}$} \\
\hline & $\begin{array}{c}\text { Coeffici } \\
\text { ent }\end{array}$ & $\begin{array}{l}\mathrm{p}- \\
\text { value }\end{array}$ & $\begin{array}{l}\text { Standard } \\
\text { Error }\end{array}$ & $\begin{array}{l}\text { Coeffic } \\
\text { ient }\end{array}$ & $\begin{array}{l}\mathrm{p}- \\
\text { value }\end{array}$ & $\begin{array}{l}\text { Standard } \\
\text { Error }\end{array}$ \\
\hline Buying cheaper foods & 0.001 & n.s & .006 & 0.008 & n.s & .007 \\
\hline Preparing frugal meals & 0.003 & n.s & .005 & -0.012 & * & .007 \\
\hline Compromising on food quality & -0.019 & $* * *$ & .006 & 0.020 & $* * *$ & .006 \\
\hline Less hospitality/socializing & -0.006 & n.s & .004 & -0.001 & n.s & .004 \\
\hline Depending on external help & 0.021 & $\star \star \star$ & .006 & 0.005 & n.s & .005 \\
\hline Constant & -2.633 & ** & 1.12 & 4.07 & $* * *$ & 1.321 \\
\hline
\end{tabular}

Unstandardized coefficients.

a Results from logit regression.

In all three models, the five ways of adapting were entered as continuous predictors. Control

variables entered into the regression were (all were entered as factorial predictors): degree of budget restriction, gender and age of the respondent, family type, housing, source of income, household disposable income (OECD modified), highest completed level of education in the household, residential area, and response mode.

$* \mathrm{p}<0.10 ; * * \mathrm{p}<0.05 ; * * * \mathrm{p}<0.01 ;$ n.s.: not significant. 
Final manuscript accepted for publication in Acta Sociologica. October 2018.

Supplementary material: Table I. Descriptive statistics - sociodemographic variables, food budget restrictions, and reasons for food budget restriction $(\mathrm{N}=1877)$

Weighted \% of the

study sample

(unweighted \%)

Socio-demographic variables $(n=1877)$

Gender

Man

$46.7(40.8)$

Woman

$53.3(59.2)$

Age

18-29 years

$8.6(13.9)$

30-44 years

$21.8(25.2)$

45-59 years

$29.3(32.4)$

60 years +

$40.4(28.4)$

Household type

Couple without children

$38.3(28.4)$

Lives alone

$27.4(16.0)$

Couple with children

$30.1(26.7)$

Single-parent with children

4.2 (29.0)

Housing

Owns house/flat

$57.1(43.8)$

Rents house/flat

$42.9(56.1)$

Source of income

Income from employment (employee- self-employed- student)

$65.2(66.7)$

Welfare benefit

$1.9(6.3)$

Disability pension

$2.9(3.1)$

Unemployment benefit

$1.4(3.1)$ 
Final manuscript accepted for publication in Acta Sociologica. October 2018.

\begin{tabular}{|c|c|}
\hline Pensioner & $28.6(20.7)$ \\
\hline \multicolumn{2}{|l|}{ Household disposable income } \\
\hline Below poverty threshold (<60\% median) & $6.1(18.4)$ \\
\hline Poverty threshold to 3 rd decile & $11.2(19.8)$ \\
\hline 3rd to 5 th decile & $30.4(29.5)$ \\
\hline 5th to 9th decile & $52.3(32.3)$ \\
\hline \multicolumn{2}{|l|}{ Highest education } \\
\hline No higher education & $21.2(20.1)$ \\
\hline High school & $4.1(8.7)$ \\
\hline Practical education & $36.9(33.0)$ \\
\hline $1-2$ years higher education & $5.3(5.3)$ \\
\hline $3-4$ years higher education & $20.7(21.6)$ \\
\hline 5 years higher education + & $11.9(11.3)$ \\
\hline \multicolumn{2}{|l|}{ Residential area } \\
\hline West Denmark & $55.5(53.5)$ \\
\hline East Denmark & 45.5 (46.5) \\
\hline
\end{tabular}

Degree of food budget restriction ( $n=1877$ )

$\begin{array}{lc}\text { Food secure } & 66.2 \\ \text { Moderately budget restricted } & 17.7 \\ \text { Severely budget restricted } & 7.8 \\ \text { Low food security } & 6.0 \\ \text { Very low food security } & 2.4\end{array}$

Reasons for food budget restrictions $(n=834)$

"Our monthly costs have increased" 14.2

"We have used more money than usual" 20.0

"Unplanned events (e.g. divorce, unemployment, lower
salary)" 
Final manuscript accepted for publication in Acta Sociologica. October 2018.

"Planned events (e.g. pension, maternity leave, educational leave)"

"Other"

29.5

No response 